\title{
One-year outcomes with the HeartMate 3 left ventricular assist device
}

Jasmin S. Hanke, MD, ${ }^{\mathrm{a}}$ Günes Dogan, MD, ${ }^{\mathrm{a}}$ Amelie Zoch, BSc, ${ }^{\mathrm{a}}$ Marcel Ricklefs, MD,

Leonhard Wert, MD, ${ }^{\text {a }}$ Christina Feldmann, $\mathrm{PhD},{ }^{\mathrm{a}}$ Christoph Bara, MD, PhD, ${ }^{\mathrm{a}}$ Malakh Shrestha, MD, PhD, ${ }^{\mathrm{a}}$

Jochen Tillmanns, MD, ${ }^{\mathrm{b}}$ Tibor Kempf, MD, PhD, ${ }^{\mathrm{b}}$ Johann Bauersachs, $\mathrm{MD}, \mathrm{PhD},{ }^{\mathrm{b}}$

Axel Haverich, MD, PhD, ${ }^{\mathrm{a}}$ and Jan D. Schmitto, MD, PhD ${ }^{\mathrm{a}}$

\section{ABSTRACT}

Background: The HeartMate 3 (HM3; Abbott Laboratories, Lake Forest, Ill) left ventricular assist device (LVAD) received its Conformité Européenne mark for Europe in October 2015 and is currently under investigation of the Food and Drug Administration to gain approval in the United States. Within this study, we present the first real-world experiences, 1-year outcomes, and adverse events of a single-center cohort treated with the HM3.

Methods: We prospectively studied midterm results of 27 consecutive patients receiving the HM3 at a single institution. After HM 3 implantation, survival, causes of death, and complications were recorded for all patients. Follow up was $100 \%$ complete.

Results: Twenty-seven patients were enrolled into the study. Within 1 year after HM3 implantation, 3 patients underwent heart transplantation and 3 patients died. Thirty-day survival was $88.9 \%$, 6-month $85.2 \%$, and 1 -year survival $85.2 \%$. No pump thrombosis and no strokes were observed within the study group. One incident of gastrointestinal bleeding was observed $(3.7 \%)$. Right heart failure was diagnosed in 1 patient after HM3 implantation (3.7\%). No technical complications of the pump were documented. No pump exchanges were necessary. The main complication was LVAD-related infection $(22.2 \%)$.

Conclusions: The novel LVAD HM3 has already shown excellent Conformité Européenne mark trial results. Within this cohort, 1-year survival after HM3 implantation was $85 \%$. The HM3 showed excellent midterm results with $0 \%$ stroke and $0 \%$ pump thrombosis rates 1 year after implantation. (J Thorac Cardiovasc Surg 2018;156:662-9)

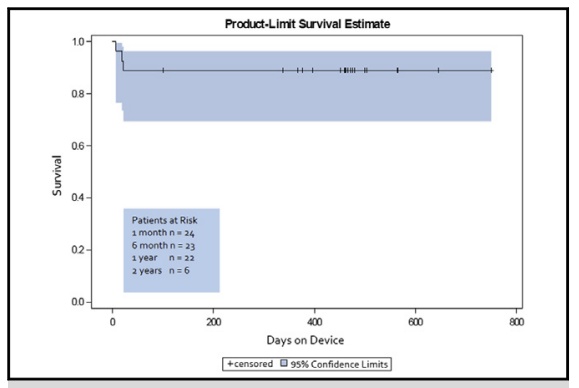

Kaplan-Meyer survival curves for the study group

\section{Central Message}

Within this cohort, 1-year survival after HM3 implantation was $85 \%$. The HM3 showed excellent midterm results, with $0 \%$ stroke and $0 \%$ pump thrombosis rates one year after implantation.

\section{Perspective}

The novel LVAD HeartMate 3 has shown excellent study results. Long-term, multicenter studies are needed to compare the long-term outcomes of therapy with the HeartMate 3.

See Editorial Commentary page 670.

See Editorial page 660.
The HeartMate 3 (HM3; Abbott Laboratories, Lake Forest, Ill) underwent its first-in-human implant in June 2014 at Hannover Medical School, Hannover, Germany, ${ }^{1}$ received its Conformité Européenne (CE) mark based on its

\footnotetext{
From the Departments of a Cardiac-, Thoracic-, Transplantation and Vascular Surgery and ${ }^{\mathrm{b}}$ Cardiology and Angiology, Hannover Medical School, Hannover, Germany.

This manuscript was kindly supported by a grant of the German Research Foundation (Deutsche Forschungsgemeinschaft, DFG) through the Project "KFO 311.'

Received for publication April 20, 2017; revisions received Jan 10, 2018; accepted for publication Jan 30, 2018; available ahead of print March 7, 2018.

Address for reprints: Jan D. Schmitto, MD, PhD, Department of CardiacThoracic-, Transplantation and Vascular Surgery Hannover Medical School, Carl-Neuberg-Str. 1, 30625 Hannover, Germany (E-mail: Schmitto.Jan@ mh-hannover.de).

$0022-5223 / \$ 36.00$

Copyright $(2) 2018$ Published by Elsevier Inc. on behalf of The American Association for Thoracic Surgery

https://doi.org/10.1016/j.jtcvs.2018.01.083
}

excellent midterm results in October 2015, ${ }^{2}$ and is currently under investigation of the US Food and Drug Administration to gain approval in the United States. New technical features such as a fully magnetically levitated pump, larger pump gaps, software improvements, and a modular driveline are promising developments and are expected to lead to superior outcomes compared with its predecessor HeartMate II (HMII; Abbott Laboratories) and other comparable assist devices.

Scanning this $\mathrm{QR}$ code will take you to a supplemental video for the article.

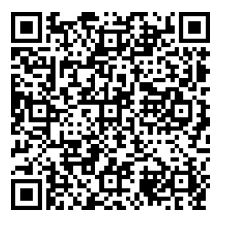




\section{Abbreviations and Acronyms \\ $\mathrm{CE}=$ Conformité Européenne \\ HM3 $=$ HeartMate 3 \\ HMII $=$ HeartMate II \\ INR $=$ international normalized ratio \\ LDH = lactate dehydrogenase \\ LVAD $\quad=$ left ventricular assist device \\ MOMENTUM 3 = Multicenter Study of MagLev \\ Technology in Patients \\ Undergoing Mechanical \\ Circulatory Support Therapy \\ with HeartMate 3 \\ $\begin{array}{ll}\text { POD } & =\text { postoperative day } \\ \text { ppy } & =\text { per patient year }\end{array}$}

In the European CE mark study, ${ }^{2,4,5}$ as well in the US-based Multicenter Study of MagLev Technology in Patients Undergoing Mechanical Circulatory Support Therapy with HeartMate 3 (MOMENTUM 3) trial, ${ }^{3}$ the HM3 presented a low adverse event profile for pump thrombosis as well as reoperation and showed excellent outcomes. Yet, real-world experience outside the study setting is rare. ${ }^{6,7}$

The Hannover group previously reported 6-month results and adverse events of therapy with the HM3 in a post-CE mark cohort. ${ }^{6}$ In this study, we now follow up on this cohort and present 1-year outcomes and complications of a single-center cohort after HM3 implantation.

\section{METHODS}

\section{Patients}

We prospectively studied a patient cohort of 27 patients who were supported with the continuous-flow left ventricular assist device (LVAD) Heartmate 3 at a single institution between June 2014 and April 2017. Of the study cohort, 8 patients were part of the HM3 CE mark trial in 2014, including the first in-human patient as of June 25, 2014. ${ }^{1}$ For the performance of this prospective study, the database of Hannover Medical School, Hannover, Germany, was used. All causes of death and adverse events were determined through examination of medical records. Only primary implantations were included in this study. Exclusion criteria were biventricular assist devices and other types of assist devices as well as LVAD exchange and reoperative procedures. All patients underwent HM3 implantation via full sternotomy via conventional technique with outflow graft anastomosis to the ascending aorta. No concomitant procedures were performed. Heparin was started 6 hours after surgery. Intravenous heparin was administered as a bridge until anticoagulation with phenprocoumon was in the therapeutic range, with a target international normalized ratio (INR) of 2.0 to 3.0 , plus aspirin at $100 \mathrm{mg} / \mathrm{d}$. Blood pressure was measured by Doppler sonography in all patients. Target blood pressure was 60 to $65 \mathrm{~mm} \mathrm{Hg}$ (mean).

\section{Study Design}

The data were prospectively collected by electronic medical record review. Baseline characteristics were obtained for all patients before HM3 implantation. After HM3 implantation, survival, causes of death, and complications were recorded for all patients. Follow-up was $100 \%$ complete. Minimal follow-up time was 12 months; maximal follow-up time was 28 months. The hospital ethical review board waived the need for patient consent to this study.

\section{Statistical Methods}

All statistical analyses were performed with Software SPSS 22 (IBM SPSS Statistics Version 22; IBM Corp, Armonk, NY). Categorical variables are reported in frequencies and continuous variables are reported as mean \pm standard deviation or as median with range if applicable. Complications (adverse events) were recorded and analyzed according to the standard Interagency Registry for Mechanically Assisted Circulatory Support (ie, INTERMACS) classifications. Survival was modeled with Kaplan-Meier curves and 95\% confidence intervals. Patients were censored in case of heart transplantation or device explantation.

\section{RESULTS}

\section{Baseline Characteristics}

This single-center study consists of 27 consecutive patients who received an HM3 device between June 2014 and April 2016 at Hannover Medical School, Hannover, Germany. Other implanted LVADs (eg, Heartmate II, Thoratec [Pleasanton, Calif]; HVAD, HeartWare [Framingham, Mass]; MVAD, HeartWare; HA5, ReliantHeart Inc [Houston, Tex]) and biventricular assist devices as well as LVAD exchanges were excluded from analysis.

Detailed baseline characteristics of the patient cohort can be found in Table 1. In total, 23.4 patient years (284.5 months; 8544 days) were analyzed. Average time on cardiopulmonary bypass was $86.6 \pm 45.0$ minutes. Average erythrocytes concentrate application until discharge was $5.1 \pm 4.7$.

Preoperatively, 1 patient in the study cohort was supported by Impella (ABIOMED, Inc, Danvers, Mass) due to a fulminant myocardial infarction. No patients were preoperatively supported by extracorporeal membrane oxygenation or intra-aortic balloon pump. The most common preoperative risk factor was pulmonary hypertension (pulmonary artery pressure mean greater than $25 \mathrm{~mm} \mathrm{Hg})(22.4 \%)$. Four $(4 / 27,14.8 \%)$ patients were diagnosed with type II diabetes. Four (4/27, 14.8\%) patients had a myocardial infarction within the last 90 days before LVAD implantation. None of the patients underwent previous cardiac surgery. ${ }^{6}$

\section{Outcomes After HM3 Implantation}

The Kaplan-Meier curve in Figure 1 illustrates the patient survival. Fifteen days after HM3 implantation, a survival of $96.3 \%(26 / 27)$ was observed in the study cohort. After 30 days, the survival rate was $89 \%, 89 \%$ after 3 months, 85\% 6 months, and 85\% 1 year after HM3 implantation.

Of 27 patients, after a timespan of 1 year, 2 patients $(2 / 27$, $7.4 \%$ ) had successfully undergone heart transplantation on postoperative day (POD) 51 and 337; 22 patients are still 
TABLE 1. Baseline characteristics of the study group

\begin{tabular}{|c|c|}
\hline & $\begin{array}{l}\text { HeartMate } \\
3 \text { patients }\end{array}$ \\
\hline Total & 27 \\
\hline Male & $25(92.6 \%)$ \\
\hline Female & $2(7.4 \%)$ \\
\hline Mean age male, y & $56.2 \pm 10.8$ \\
\hline Mean age female, $y$ & $63 \pm 4.2$ \\
\hline Mean body mass index, $\mathrm{kg} / \mathrm{m}^{2}$ & 27.95 \\
\hline Mean body surface area, $\mathrm{m}^{2}$ & 2.06 \\
\hline $\begin{array}{l}\text { Diagnoses } \\
\text { Dilated cardiomyopathy } \\
\text { Ischemic cardiomyopathy }\end{array}$ & $\begin{array}{r}18(66.7 \%) \\
9(33.3 \%)\end{array}$ \\
\hline $\begin{array}{l}\text { NYHA profile } \\
\text { IV } \\
\text { III }\end{array}$ & $\begin{array}{c}26(96.3 \%) \\
1(3.7 \%)\end{array}$ \\
\hline $\begin{array}{l}\text { INTERMACS profile } \\
\text { I } \\
\text { II } \\
\text { III } \\
\text { IV }\end{array}$ & $\begin{array}{c}1(3.7 \%) \\
2(7.4 \%) \\
23(85.2 \%) \\
1(3.7 \%)\end{array}$ \\
\hline $\begin{array}{l}\text { Stay } \\
\text { Mean postoperative length of stay } \\
\text { after LVAD implantation, } d \\
\text { Mean ICU stay, } d\end{array}$ & $\begin{array}{l}21.9 \pm 9.4 \\
3.6 \pm 2.7\end{array}$ \\
\hline Mean cardiopulmonary bypass time, $\min$ & $86.6 \pm 45.0$ \\
\hline Mean packed red blood cells until discharge & $5.1 \pm 4.7$ \\
\hline Mean epinephrine support, $d$ & $5.81(2.46-9.16)$ \\
\hline Mean milrinone support, $\mathrm{d}$ & $4.50(2.44-6.56)$ \\
\hline \multicolumn{2}{|l|}{ Preoperative right heart catheter } \\
\hline $\begin{array}{l}\text { Mean } \\
\text { Mean pulmonary artery pressure, } \mathrm{mm} \mathrm{Hg}\end{array}$ & $11.3 \pm 2.5$ \\
\hline $\begin{array}{l}\text { Systolic } \\
\text { Diastolic } \\
\text { Mean } \\
\text { Mean preimplant cardiac index, } \mathrm{L} / \mathrm{min} / \mathrm{sqm}\end{array}$ & $\begin{aligned} 52.3 & \pm 23.2 \\
23.9 & \pm 10.4 \\
34.8 & \pm 15.3 \\
1.9 & \pm 0.4\end{aligned}$ \\
\hline \multicolumn{2}{|l|}{ Echocardiography } \\
\hline $\begin{array}{l}\text { Mean preoperative LV ejection fraction (Echo) } \\
\text { Mean preoperative LV ejection fraction (catheter) } \\
\text { Mean preoperative LV end-diastolic diameter } \\
\text { Mean predischarge LV end-diastolic diameter } \\
\text { Preoperative mitral valve insufficiency }\end{array}$ & $\begin{array}{c}24.3 \pm 11.1 \\
19.1 \pm 7.3 \\
75.9 \pm 11.1 \\
64.5 \pm 13.2\end{array}$ \\
\hline $\begin{array}{l}0 \\
\text { I } \\
\text { II }\end{array}$ & $\begin{array}{r}9(33.3 \%) \\
12(44.4 \%) \\
5(18.5 \%)\end{array}$ \\
\hline \multicolumn{2}{|l|}{ Preoperative tricuspid valve insufficiency } \\
\hline 0 & $6(22.2 \%)$ \\
\hline I & $9(33.3 \%)$ \\
\hline II & $8(29.6 \%)$ \\
\hline III & $4(14.8 \%)$ \\
\hline
\end{tabular}

TABLE 1. Continued

\begin{tabular}{ll}
\hline & $\begin{array}{c}\text { HeartMate } \\
\text { 3 patients }\end{array}$ \\
\hline Status & \\
Cardiac transplantation & $2(7.4 \%)$ \\
LVAD explantation due to recovery & $0(0 \%)$ \\
Death after LVAD implantation & $3(11.1 \%)$ \\
\hline
\end{tabular}

NYHA, New York Heart Association; INTERMACS, Interagency Registry for Mechanically Assisted Circulatory Support; $L V A D$, left ventricular assist device; $I C U$, intensive care unit; $L V$, left ventricular.

ongoing on the device. The longest ongoing patient out of the HM3 study is on device for more than 2.5 years as of April 1, 2017.

\section{Causes of Death}

One year after HM3 implantation, of 27 patients, 3 patients died. All deceased patients died in the early postoperative course. The first patient died on POD 17 due to pneumonic sepsis. The second and the third patient died on POD 7 and POD 22 due to multiorgan failure including right heart failure.

\section{Complications 1 Year After HM3 Implantation}

Adverse events are listed in Table 2. A total of 12 bleeding events were observed in 8 patients of the study group $(8 / 27,29.6 \%)$. Of those, one was a gastrointestinal bleeding event $(3.7 \%, 0.0428583$ events per patient year [ppy]) and one a late tamponade that required rethoracotomy (3.7\%, 0.0428583 events ppy).

No case of pump thrombosis or pump dysfunction was recorded in the cohort. No case of either hemorrhagic or embolic stroke was observed in the study group.

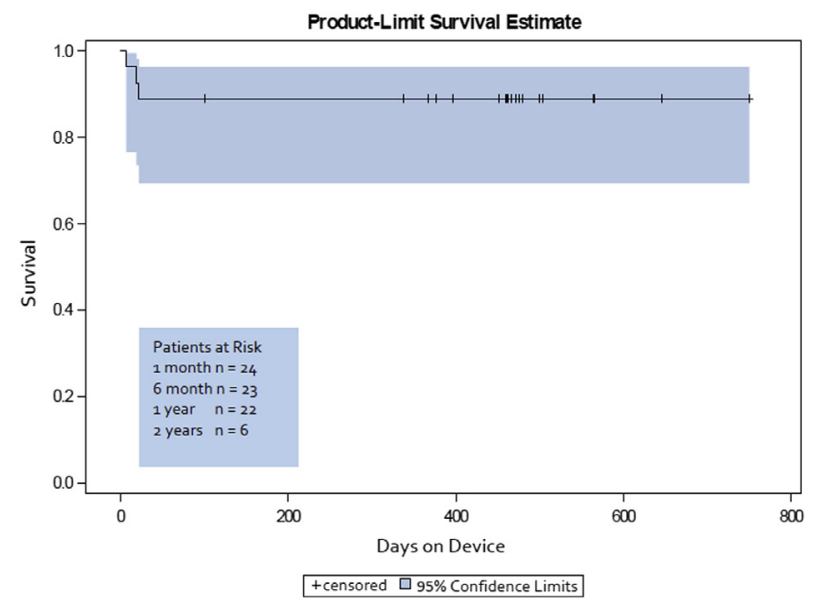

FIGURE 1. Kaplan-Meyer survival curves presenting the survival of the study group one year after HeartMate 3 implantation. Time to death was modeled using Kaplan-Meier curves and 95\% confidence limits. Participants were censored when the device was explanted or in case of cardiac transplantation. 
TABLE 2. Adverse events in the study cohort

\begin{tabular}{|c|c|c|c|c|c|c|c|c|c|c|c|}
\hline & \multicolumn{2}{|c|}{$\begin{array}{c}1 \mathrm{mo} \\
\mathrm{n}=27\end{array}$} & \multicolumn{2}{|c|}{$\begin{array}{c}3 \text { mo } \\
n=24\end{array}$} & \multicolumn{2}{|c|}{$\begin{array}{c}6 \mathrm{mo} \\
\mathrm{n}=23\end{array}$} & \multicolumn{2}{|c|}{$\begin{array}{l}>6 \mathrm{mo} \\
\mathrm{n}=23\end{array}$} & \multicolumn{2}{|c|}{$\begin{array}{c}\text { All }(1 \mathbf{y}) \\
\mathbf{n}=27\end{array}$} & \multirow{2}{*}{$\begin{array}{l}\text { Events per } \\
\text { patient year }\end{array}$} \\
\hline & $\overline{\text { Patients }}$ & $\overline{\text { Events }}$ & $\overline{\text { Patients }}$ & Events & $\overline{\text { Patients }}$ & Events & $\overline{\text { Patients }}$ & Events & $\overline{\text { Patients }}$ & $\overline{\text { Events }}$ & \\
\hline \multicolumn{12}{|l|}{$\overline{\text { Bleeding }}$} \\
\hline Bleeding event & 6 & 8 & 3 & 3 & 0 & 0 & 1 & 1 & 8 & 12 & 0.0422733 \\
\hline Requiring surgery & 1 & 0 & 0 & 1 & 0 & 0 & 0 & 0 & 1 & 1 & 0.0035226 \\
\hline GI bleeding & 1 & 1 & 0 & 0 & 0 & 0 & 0 & 0 & 1 & 1 & 0.0035226 \\
\hline Pump thrombosis & 0 & 0 & 0 & 0 & 0 & 0 & 0 & 0 & 0 & 0 & 0 \\
\hline Technical complication & 0 & 0 & 0 & 0 & 0 & 0 & 0 & 0 & 0 & 0 & 0 \\
\hline \multicolumn{12}{|l|}{ Infection } \\
\hline LVAD related & 2 & 2 & 1 & 2 & 0 & 0 & 4 & 2 & 6 & 8 & 0.0281822 \\
\hline Non-LVAD related & 7 & 8 & 0 & 0 & 0 & 0 & 1 & 1 & 7 & 9 & 0.0317050 \\
\hline Right heart failure & 1 & 1 & 1 & 1 & 0 & 0 & 0 & 0 & 2 & 2 & 0.00023485 \\
\hline Stroke & 0 & 0 & 0 & 0 & 0 & 0 & 0 & 0 & 0 & 0 & 0 \\
\hline
\end{tabular}

GI, Gastrointestinal; $L V A D$, left ventricular assist device.

Two patients were diagnosed with coagulations disorder $(7.4 \%)$. Both cases were classified as von-Willebrand factor deficiency.

Infection remained the major complication 1 year after HM3 implantation, with 8 LVAD-related events in 6 patients $(22.2 \%, 0.3428839$ events ppy). Seven patients presented with 9 events of non-LVAD-related infections $(25.9 \%, 0.3857429$ events ppy).
Right heart failure was diagnosed in 2 patients $(2 / 27$, $7.4 \%, 0.0857202$ events ppy) in the early postoperative course. Both patients died in the first month after HM3 implantation.

\section{Pre- and Postoperative Organ Function}

Pre- and postoperative laboratory values are presented in Figure 2. Liver parameters alanine transaminase $(\mathrm{U} / \mathrm{L})$ and

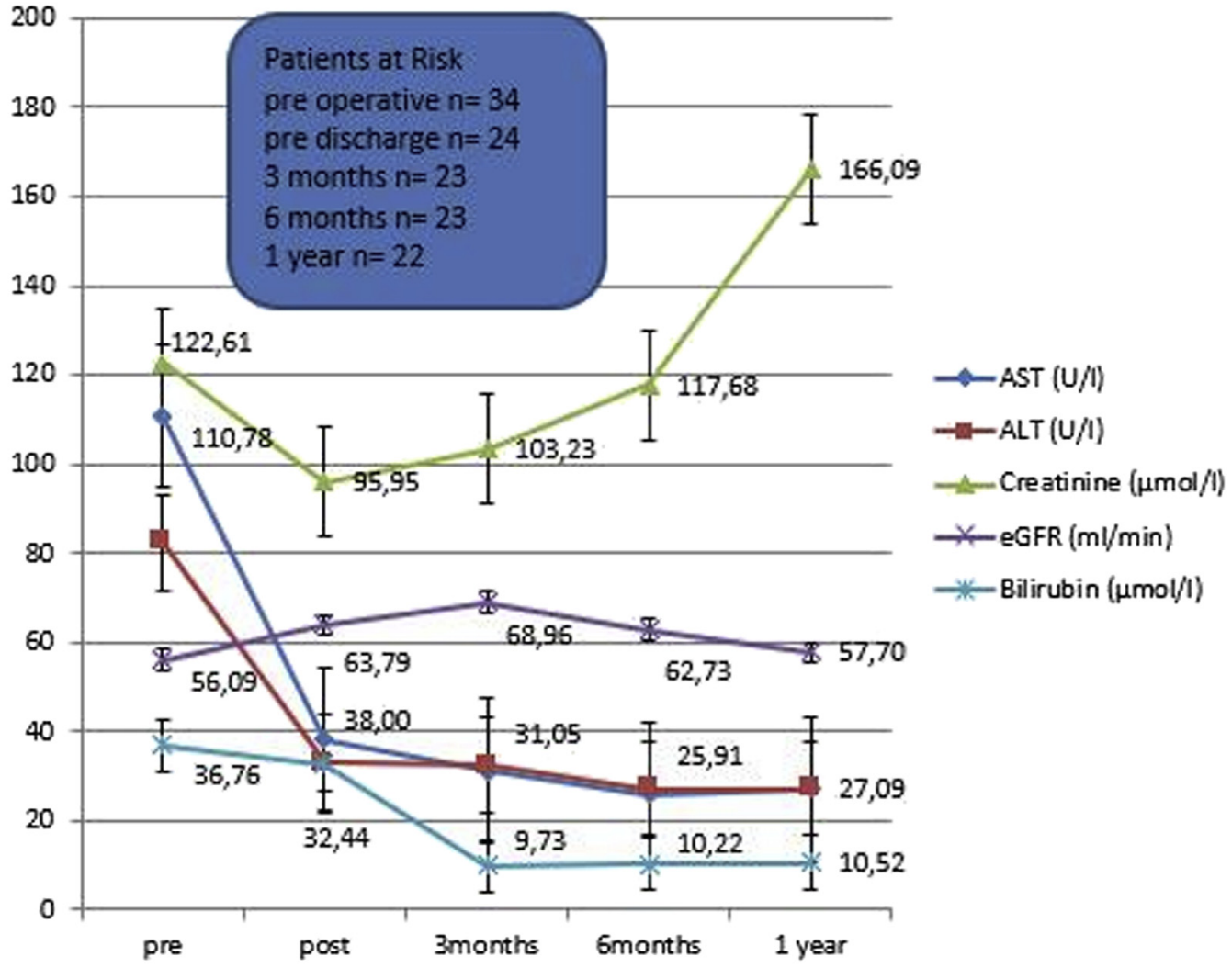

FIGURE 2. Pre- and postoperative laboratory parameters presenting liver and renal function 1 year after HeartMate 3 implantation. AST, Aspartate aminotransferase; $A L T$, alanine transaminase; $e G F R$, estimated glomerular filtration rate. 


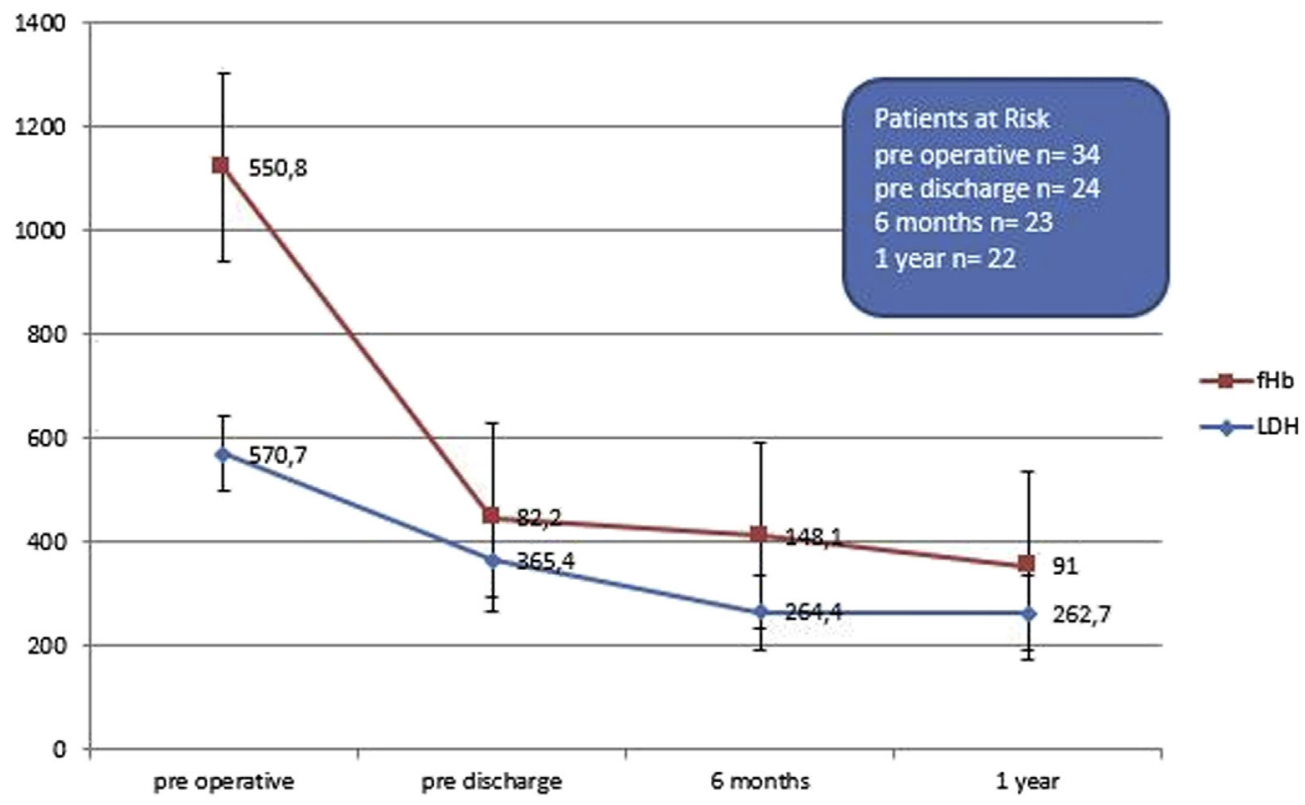

FIGURE 3. Hemolysis parameters: $\mathrm{LDH}(\mathrm{U} / \mathrm{L})$ and $\mathrm{fHb}(\mathrm{mg} / \mathrm{L})$ levels after HeartMate 3 implantation. $f H b$, Free hemoglobin; $L D H$, lactate dehydrogenase.

aspartate aminotransferase (U/L) as well as bilirubin $(\mu \mathrm{mol} / \mathrm{L})$ showed a steep decline until the sixth postoperative month (mean aspartate aminotransferase 27.1 U/L, mean alanine transaminase $27.0 \mathrm{U} / \mathrm{L}$, mean bilirubin $10.5 \mu \mathrm{mol} / \mathrm{L}$ ) Mean creatinine and glomerular filtration rate decreased in the first postoperative month but reached elevated levels 1 year after implantation (mean creatinine $166.1 \mu \mathrm{mol} / \mathrm{L}$, mean glomerular filtration rate $57.7 \mathrm{~mL} / \mathrm{min})$.

\section{Lactate Dehydrogenase (LDH) and Free Hemoglobin}

The average LDH (U/L) as well as free hemoglobin $(\mathrm{mg} / \mathrm{L})$ laboratory values are displayed in Figure 3. The free hemoglobin curve shows a steep decline, followed by a slight increase in the sixth postoperative month and declines again until 1 year after implantation to $91 \pm 56.1 \mathrm{mg} / \mathrm{L}$. LDH levels showed a decrease during the entire study period and reached a steady level of mean $262.7 \pm 56.5 \mathrm{U} / \mathrm{L}$ at 1 year after implantation.

\section{LVAD Parameters After HM3 Implantation}

LVAD parameters after implantation are depicted in Table 3. One month after implantation the average speed was 5365 RPM, after 6 months 5552 RPM, and after 12 months 5581 RPM. Mean power was $3.77 \mathrm{~W}$ after 1 month, $4.33 \mathrm{~W}$ after 6 months, and $4.30 \mathrm{~W}$ after 12 months of LVAD support.

\section{DISCUSSION}

The European CE Mark trial ${ }^{1,2,4,5}$ as well as the US-based MOMENTUM 3 data $^{3}$ already showed excellent short-to-midterm results for HM3. The HM3 CE Mark trial showed a 6-month survival of $92 \%$, and the MOMENTUM 3 trial showed a 6-month survival of $86.2 \%$ in the study group. ${ }^{2,3}$ We previously reported a 6-month outcome of $85 \%$ of the presented cohort, ${ }^{6}$ without any additional deaths. The 1-year outcome of our cohort remained at $85 \%$.

Real-world experience of therapy with the HM3 is rare (Table 4). Ozturk and colleagues ${ }^{7}$ presented their short-term results of 8 patients who received HM3. The data show that HM3 implantation in their institution is associated with decreased bleeding complications and blood product administration as well as shorter implantation times compared with patients who received HMII.

Recently, the 1-year results of the HM3 CE mark study have been published. ${ }^{5}$ One-year survival was $74 \%$,

TABLE 3. LVAD parameters and settings after HM3 implantation

\begin{tabular}{lccc}
\hline & 1. POD & 6 mo & 12 mo \\
\hline Pump speed & & & \\
Mean RPM & 5365 & 5552 & 5581 \\
$\quad$ Range (upper limit) & 5707 & 5944 & 5972 \\
$\quad$ Range (lower limit) & 5023 & 5160 & 5191 \\
Power & & & \\
$\quad$ Mean Watts & 3.77 & 4.33 & 4.30 \\
$\quad$ Range (upper limit) & 4.18 & 4.93 & 4.88 \\
$\quad$ Range (lower limit) & 3.36 & 3.73 & 3.71 \\
Pulsatility index & & & \\
Mean & 3.54 & 4.17 & 4.21 \\
$\quad$ Range (upper limit) & 4.48 & 5.57 & 5.47 \\
$\quad$ Range (lower limit) & 2.60 & 2.77 & 2.95 \\
\hline
\end{tabular}

$P O D$, Postoperative day; $R P M$, rotations per minute. 
TABLE 4. Literature overview on HeartMate 3

\begin{tabular}{|c|c|c|c|c|c|c|c|c|}
\hline Authors & Paper & $\begin{array}{c}\text { No. } \\
\text { patients } \\
\end{array}$ & $\begin{array}{c}\text { Trial } \\
\text { period }\end{array}$ & Follow-up & $\begin{array}{c}\text { Pump } \\
\text { thrombosis }\end{array}$ & Stroke & Survival & $\begin{array}{c}\text { Bleeding } \\
\text { complications }\end{array}$ \\
\hline $\begin{array}{l}\text { Schmitto } \\
\text { et al, } \\
2015^{1}\end{array}$ & $\begin{array}{l}\text { First implantation } \\
\text { in man of a new } \\
\text { magnetically } \\
\text { levitated left } \\
\text { ventricular } \\
\text { assist device } \\
\text { (HeartMate 3) }\end{array}$ & 1 & June 25, 2014 & $\begin{array}{l}\text { None. } \\
\text { Case report }\end{array}$ & None & $\begin{array}{l}1 \text { seizure on POD } \\
14\end{array}$ & $100 \%$ & - \\
\hline $\begin{array}{l}\text { Zimpfer } \\
\text { et al, } \\
2016^{4}\end{array}$ & $\begin{array}{l}\text { Multicentre } \\
\text { clinical trial } \\
\text { experience with } \\
\text { the HeartMate } 3 \\
\text { left ventricular } \\
\text { assist device: } \\
\text { 30-d outcomes }\end{array}$ & 50 & $\begin{array}{l}\text { June to November } \\
2014\end{array}$ & $30 \mathrm{~d}$ & None & $2(4 \%)$ & $98 \%$ & $\begin{array}{l}6 \text { patients }(12 \%) \\
\text { reoperation for } \\
\text { postoperative } \\
\text { bleeding }\end{array}$ \\
\hline $\begin{array}{l}\text { Mehra } \\
\text { et al, } \\
2017^{3}\end{array}$ & $\begin{array}{l}\text { A Fully } \\
\text { magnetically } \\
\text { levitated } \\
\text { circulatory } \\
\text { pump for } \\
\text { advanced heart } \\
\text { failure }\end{array}$ & 294 & $\begin{array}{c}\text { September } 2014 \text { to } \\
\text { October } 2015\end{array}$ & $6 \mathrm{mo}$ & None & $\begin{array}{l}\text { Ischemic } \\
\text { (8 patients, } \\
8 \text { events) } \\
\text { Hemorrhagic } \\
\text { (4 patients, } \\
4 \text { events) } \\
\text { Disabling } \\
\text { (9 patients, } \\
9 \text { events) }\end{array}$ & $86 \%$ & $\begin{array}{l}\text { Any bleeding: } \\
100 \text { events } \\
\text { in } 50 \text { patients } \\
(33.1 \%) \\
\text { GI bleeding: } \\
47 \text { events } \\
\text { in } 24 \text { patients } \\
(15.9 \%) \\
\text { Bleeding requiring } \\
\text { surgery: } 15 \\
\text { events in } 15 \\
\text { patients }(9.9 \%)\end{array}$ \\
\hline $\begin{array}{l}\text { Ozturk } \\
\text { et al, } \\
2017^{7}\end{array}$ & $\begin{array}{l}\text { Short-term results } \\
\text { of HeartMate } 3 \\
\text { ventricular } \\
\text { assist device } \\
\text { implantation for } \\
\text { end-stage heart } \\
\text { failure }\end{array}$ & 8 & $\begin{array}{l}\text { January to June } \\
2016\end{array}$ & $30 \mathrm{~d}$ & None & $\begin{array}{l}\text { No stroke required } \\
\text { surgery }\end{array}$ & $100 \%$ & $\begin{array}{l}\text { No major bleeding } \\
\text { event for } \\
\text { HeartMate } 3 \text {. }\end{array}$ \\
\hline $\begin{array}{l}\text { Krabatsch } \\
\text { et al, } \\
2017^{5}\end{array}$ & $\begin{array}{l}\text { HeartMate } 3 \text { fully } \\
\text { magnetically } \\
\text { levitated left } \\
\text { ventricular } \\
\text { assist device for } \\
\text { the treatment of } \\
\text { advanced heart } \\
\text { failure-1 y } \\
\text { results from the } \\
\text { CE-mark trial }\end{array}$ & 50 & $\begin{array}{l}\text { June to November } \\
2014\end{array}$ & One year & None & $\begin{array}{l}\text { Ischemic } \\
\text { (4 patients, } \\
4 \text { events) } \\
\text { Hemorrhagic } \\
\text { ( } 2 \text { patients, } \\
2 \text { events) }\end{array}$ & $81 \% \pm 6 \%$ & $12 \%$ GI bleeding \\
\hline $\begin{array}{l}\text { Hanke } \\
\text { et al, } \\
2017^{6}\end{array}$ & $\begin{array}{c}\text { First experiences } \\
\text { with HeartMate } \\
3 \text { follow-up and } \\
\text { adverse events }\end{array}$ & 27 & $\begin{array}{r}\text { June } 2014 \text { to } \\
\text { April } 2016\end{array}$ & Six months & None & None & $\begin{array}{l}88.9 \%(30 d) \\
85.2 \%(60 d)\end{array}$ & $\begin{array}{l}30 \mathrm{~d} \text { : minor } \\
\text { bleeding: } \\
8 \text { events } \\
\text { in } 6 \text { patients } \\
(22.2 \%) \\
\text { GI bleeding: } 1 \\
\text { patient }(3.7 \%) \text {. } \\
60 \text { d: Bleeding: } \\
12 \text { events in } 8\end{array}$ \\
\hline
\end{tabular}


TABLE 4. Continued

\begin{tabular}{|c|c|c|c|c|c|c|c|c|}
\hline Authors & Paper & $\begin{array}{c}\text { No. } \\
\text { patients }\end{array}$ & $\begin{array}{c}\text { Trial } \\
\text { period }\end{array}$ & Follow-up & $\begin{array}{c}\text { Pump } \\
\text { thrombosis }\end{array}$ & Stroke & Survival & $\begin{array}{c}\text { Bleeding } \\
\text { complications }\end{array}$ \\
\hline & & & & & & & & $\begin{array}{l}\text { patients, } 1 \\
\text { requiring } \\
\text { surgery }(3.7 \%) \\
\text { GI bleeding: } 1 \\
\text { patient }(3.7 \%)\end{array}$ \\
\hline
\end{tabular}

$P O D$, Postoperative day; $G I$, gastrointestinal.

with $6 \%$ cardiac transplantations and $2 \%$ explantations due to cardiac recovery. Main complications of the study group were $12 \%$ gastrointestinal bleeding, $16 \%$ driveline infections, and $18 \%$ strokes. Again, no pump thrombosis or malfunctions were observed in the study cohort. ${ }^{5}$

So far, in the 1-year follow-up, no pump thrombosis was observed in our patient cohort. In accordance with our results, the CE Mark Study as well as the MOMENTUM trial also reported no pump thrombosis respectively. ${ }^{1-5}$ Debilitating strokes were reported in $7.9 \%$ of the patients in the MOMENTUM trial ${ }^{3}$ and in $18 \%$ of the patients in the 1-year follow-up of the CE mark study ${ }^{5}$ In our patient population, also 1 year after HM3 implantation, no strokes were observed.

According to study protocols, anticoagulation of HM3 was in the therapeutic range, with a target INR of 2.0 to 3.0 , plus aspirin at $100 \mathrm{mg} / \mathrm{d}$. One gastrointestinal bleeding was observed (3.7\%). The 1-year CE Mark and the 6 months MOMENTUM 3 data indicate rates of $12 \%$ and $11.9 \%$, respectively. ${ }^{3,5}$ Hemocompatibility of the HM3 was investigated in a secondary analysis of the MOMENTUM 3 data by Uriel and colleagues ${ }^{8}$ to evaluate the aggregate of hemocompatibility-related clinical adverse events. This subanalysis also demonstrated a reduced adverse event profile for the HM3 compared with the HMII.

Consecutively, because of the trend for a low rate of pump thrombosis throughout the currently published studies on HM3, it should be assessed whether a reduction of anticoagulation is possible with the new device, eg, lowering the risk of gastrointestinal bleedings.

Anticoagulation is a major factor in preventing pump thrombosis. Yet, too-strict regimens increase the risk of bleeding complications such as gastrointestinal bleeding or hemorrhagic stroke. The Study of Reduced Anti-Coagulation/Anti-Platelet Therapy in Patients With the HeartMate II LVAS (TRACE) study questioned the need of double anticoagulation in patients with HMII to reduce the risk of pump thrombosis. The 1-year results revealed that reducing antithrombotic therapies in response to bleeding among patients with HMII was achievable but may be associated with a greater risk for device thrombosis. ${ }^{9}$ However, the recently published 2-year results showed that managing patients undergoing HMII with a vitamin $\mathrm{K}$ antagonist with a target INR of 2.3 without antiplatelet therapy may help to reduce the incidence of major bleeding without increasing the risk of thromboembolic events, including ischemic stroke and pump thrombosis. ${ }^{10}$ Consequently, a multicenter trial with a reduction of anticoagulation for the HM3 should be discussed.

High-pump speeds $\geq 9000$ RPMs for the HMII are associated with a lower risk for pump thrombosis. ${ }^{11} \mathrm{~A}$ total of 15 patients who received HM3 underwent ramp study testing with right heart catheterization including central venous pressure, pulmonary artery pressure, pulmonary capillary wedge pressure, blood pressure, and 3-dimensional echocardiography ${ }^{12} 6$ months after HM3 implantation. LVAD RPMs (rotations per minute) were set to achieve normal wedge as well as central venous pressures to result in improved physiologic flow in the circulatory system. According to the authors, hemodynamic normalization of pressures was achieved in the majority of patients implanted with the HM3 pump within a narrow speed range. ${ }^{12}$ Careful re-evaluation of HM3 pump settings should therefore be regularly performed to achieve best results.

Surgical pump exchange is a possible treatment option for pump thrombosis. Because of the significant reduction in the rate of pump thrombosis compared with the HMII, a device upgrade to HM3 should be discussed as a treatment option.

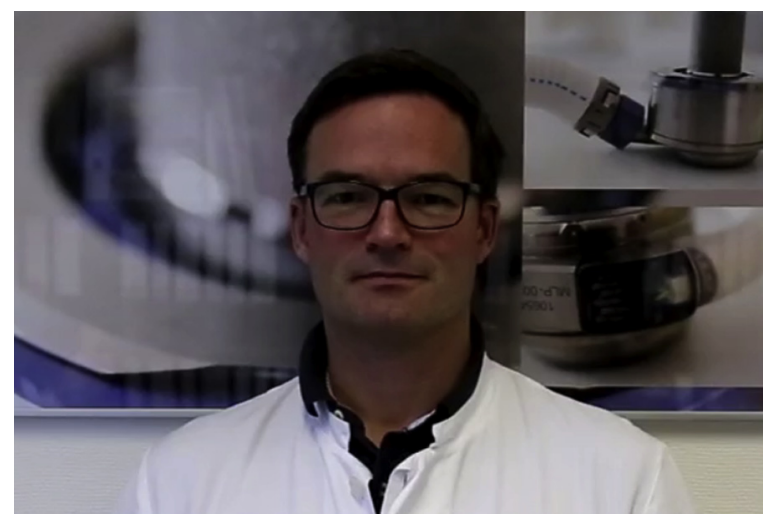

VIDEO 1. Senior author Professor Dr Jan D. Schmitto, MBA, FCCP, FRCS (Glasg.), FACS, on the HeartMate 3 and the result of this study. Video available at: http://www.jtcvsonline.org/article/S0022-5223(18) 30360-X/fulltext. 
Other reported adverse events of the MOMENTUM 3 as well the CE mark trial were observed in similar rates in our study population. In summary, device-related infections and bleeding complications remain major challenges in patients with LVADs and prevention is of upmost importance (Video 1). ${ }^{13}$

\section{Limitations}

This study has several limitations. All implantations were performed at a single center and therefore reproducibility may be limited and is affected by institutional experience. The results of surgical studies are prone to learning curves and a single center's specific characteristics. Moreover, the study period began 3 years ago. Therapeutic strategies and increased clinical experience might improve today's results.

In addition, the number of patients on the new device was small, which in turn reduces the precision of our estimates. This is reflected for example, by the wide confidence intervals in the Kaplan-Meier curve. Therefore, the small sample size of the cohort limits the precision of the results of this study. As such, large-sample, real-world studies on the outcomes of patients with HM3 need to be performed. Furthermore, this study is limited to a single left ventricular assist device and does not compare the outcomes of other comparable assist devices. Larger, prospective, randomized controlled studies are worthwhile to compare the long-term outcomes of different types of assist devices.

\section{CONCLUSIONS}

The novel LVAD HM3 has already shown excellent CE mark trial results. After 1 year of therapy, the survival in our study group is $85 \%$. The HM3 continued to show a low adverse event rate profile without stroke and pump thrombosis one year after implantation.

\section{Conflict of Interest Statement}

J.D.S. and G.D. receive consultation fees from Abbott. All other authors have nothing to disclose with regard to commercial support.

\section{References}

1. Schmitto JD, Hanke JS, Rojas SV, Avsar M, Haverich A. First implantation in man of a new magnetically levitated left ventricular assist device (HeartMate III). J Heart Lung Transplant. 2015;34:858-60.

2. Netuka I, Sood P, Pya Y, Zimpfer D, Krabatsch T, Garbade J, et al. Fully magnetically levitated left ventricular assist system for treating advanced HF: a multicenter study. J Am Coll Cardiol. 2015;66:2579-89.

3. Mehra MR, Naka Y, Uriel N, Goldstein DJ, Cleveland JC Jr, Colombo PC, et al; MOMENTUM 3 Investigators. A fully magnetically levitated circulatory pump for advanced heart failure. $N$ Engl J Med. 2017;376:440-50.

4. Zimpfer D, Netuka I, Schmitto JD, Pya Y, Garbade J, Morshuis M, et al. Multicentre clinical trial experience with the HeartMate 3 lef ventricular assist device: 30-day outcomes. Eur J Cardiothorac Surg. 2016;50:548-54

5. Krabatsch T, Netuka I, Schmitto JD, Zimpfer D, Garbade J, Rao V, et al. Heartmate 3 fully magnetically levitated left ventricular assist device for the treatment of advanced heart failure-1 year results from the CE mark trial. J Cardiothorac Surg. 2017;12:23.

6. Hanke JS, Dogan G, Rojas SV, Zoch A, Feldmann C, Deniz E, et al. First experiences with HeartMate 3 follow-up and adverse events. J Thorac Cardiovasc Surg. 2017;154:173-8.

7. Ozturk P, Ertugay S, Sahutoglu C, Engin C, Nalbantgil S, Yagdi T, et al. Short-term results of Heartmate 3 ventricular assist device implantation for end-stage heart failure. Transplant Proc. 2017;49:599-602.

8. Uriel N, Colombo PC, Cleveland JC, Long JW, Salerno C, Goldstein DJ, et al. Hemocompatibility-related outcomes in the MOMENTUM 3 trial at 6 months: a randomized controlled study of a fully magnetically levitated pump in advanced heart failure. Circulation. 2017;135:2003-12.

9. Katz JN, Adamson RM, John R, Tatooles A, Sundareswaran K, Kallel F, et al; TRACE Study. Safety of reduced anti-thrombotic strategies in HeartMate II patients: a one-year analysis of the US-TRACE study. J Heart Lung Transplant. 2015;34:1542-8.

10. Netuka I, Litzler PY, Berchtold-Herz M, Flecher E, Zimpfer D, Damme L, et al EU TRACE Investigators. Outcomes in HeartMate II patients with no antiplatelet therapy: 2-year results from the European TRACE study. Ann Thorac Surg. 2017; 103:1262-8

11. Maltais S, Kilic A, Nathan S, Keebler M, Emani S, Ransom J, et al; PREVENT Study Investigators. PREVENtion of HeartMate II pump thrombosis through clinical management: the PREVENT multi-center study. J Heart Lung Transplant. 2017;36:1-12.

12. Uriel N, Adatya S, Malý J, Kruse E, Rodgers D, Heatley G, et al. Clinical hemodynamic evaluation of patients implanted with a fully magnetically levitated left ventricular assist device (HeartMate 3). J Heart Lung Transplant. 2017;36:28-35.

13. Rao V. HeartMate 3-Better...but not perfect. J Thorac Cardiovasc Surg. 2017; $154: 179-80$

Key Words: LVAD, left ventricular assist device, HeartMate 3, outcomes, complications, pump thrombosis, driveline infection, one year, survival 